\title{
Grasping and Interaction Force Feedback in Microassembly
}

\author{
Marcello Porta and Marcel Tichem
}

\begin{abstract}
Department of Precision and Microsystems Engineering (PME), Delft University of Technology (TU Delft), Mekelweg 2, 2628CD, Delft, The Netherlands m.porta@tudelft.nl, m.tichem@tudelft.nl
\end{abstract}

\begin{abstract}
The aim of this paper is to define role and added value of force feedback in executing microassembly tasks, as well as to demonstrate microsystem technology based sensing devices which allow registering the relevant forces. In executing microassembly processes useful forces to sense are the grasping force, i.e. the force with which the object is gripped, and the interaction force, i.e. the force resulting from the interaction of the gripped object with the environment. Based on a general assembly process analysis, the requirements for force sensing are defined. Next, devices are shown which allow the identification of the contact forces and object positions.
\end{abstract}

Keywords: Microassembly, Force sensing, Grasping force, Interaction Force.

\section{Introduction}

In the assembly of microproducts the feedback of the status of the ongoing process is a key element for the successful completion of the tasks [1], [2], [3]. This feedback can be either visual information or force information. The grasping force monitoring (i.e. the force with which the object is gripped) prevents damaging delicate and fragile components (such as micro-lenses; micro-capillary-tubes). The interaction force sensing (i.e. the force resulting from the interaction of the gripped object, or the gripper itself, with the environment) is useful for speeding up the process and sometimes necessary for successfully completing the tasks (such as peg-in-hole with low clearance, engagement of micro-gears). Fig. 1 provides some significant examples.

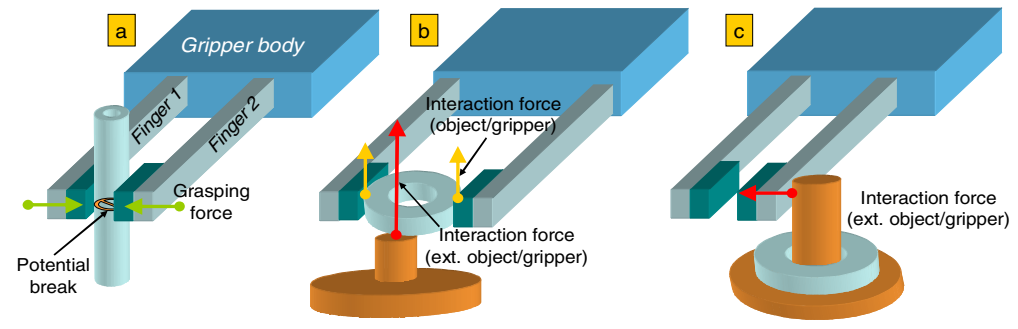

Fig. 1. Operations in which the monitoring of the grasping and interaction forces is important: (a) grasping of a fragile micro-cylinder; (b) peg-in-hole task; (c) interaction between the gripper and a sub assembled product. 


\section{Grasping and Interaction Force Sensing in Microhandling}

Many devices have been developed for detecting grasping and interaction forces in microassembly and microhandling.

The grasping force is usually detected by two fingers mechanical micro-grippers equipped with sensors [4], [5], [6], [7], [8], [9], [10]. Some of these grippers are also able to sense interaction force, along one degree of freedom (DOF), perpendicular [4], [5] or parallel [6] to the grasping plane (i.e. the plane defined by the opening and closing of the fingers of the gripper).

The performance of the micro-grippers in terms of stroke, force resolution and maximum force depends on the adopted actuators and sensors, the material of the mechanical structure of the gripper and the mechanical amplification. Usually, there is a trade-off between stroke and force resolution and between maximum force and force resolution. This trade off is evident in the two main types of micro-grippers: siliconbased micro-grippers [5], [6], [9], [10] and hybrid micro-grippers [4], [7], [8]. The silicon micro-grippers usually offer the best resolution while the hybrid ones the best stroke and the maximum grasping force.

Silicon micro-grippers are directly fabricated with integrated actuators (electrostatic [9] or thermal [6], [10]) and sensors (piezoresistors [5], [10] or capacitive sensors [6], [9]). In hybrid micro-grippers the mechanical structure of the grippers, the actuators (piezo-elements [4], [8], electromagnets [7] or SMA actuators [8]) and sensors (usually strain gauges [4], [8] glued or fixed to the mechanical structure) are produced separately and then assembled together.

The selection of one of the two main types of microgrippers, their mechanical design, the adopted sensors and actuators depends on the microparts to grasp and the handling applications.

The interaction forces sensing along many DOF (till 6) is normally obtained by devices placed in the interface between the gripper and the manipulator supporting the gripper [11], [12], [13], [14].

The performance of the interaction force sensing devices in terms of force/torque resolution and maximum force/torque depend both on the mechanical structure of the device and the type of sensor used for detect the forces. Usually, the bigger is the maximum detectable force and the worse is the sensing resolution. Silicon-based devices with embedded sensors (piezoresistor [12], capacitive sensors [11], or piezoelectric elements [13]) often present a much better resolution and a lower operational range than devices with external strain gauges glued or fixed on them [14].

\section{Force Feedback Requirement Definition}

In order to define the role of feedback in microassembly, and in particular the force feedback, Table 1 analyzes an abstract and general microassembly operation. The table points out the feedback that can avoid the different failures in exploiting the subtasks. The general microassembly operation is supposed to be composed by four main sub-tasks: grasping, moving, positioning and releasing of a micro-part. The available feedbacks are visual feedback, grasping force feedback and interaction force feedback. For every possible failure, the table reports what is the type of control and the 
required information to detect the failure. Then, it suggests a type of feedback which is possibly useful for the control system to take an appropriate action for solving the identified failure. For every feedback three different levels of reliability (low, medium, high) are given. This reliability level quantifies the efficacy and the efficiency of any feedback in avoiding the particular failure.

Table 1. Failures and successes related to feedback in the general microassembly operation

\begin{tabular}{|c|c|c|c|c|c|c|}
\hline \multirow[t]{2}{*}{ SUB TASK } & \multirow[t]{2}{*}{ TYPE OF CONTROL } & \multirow[t]{2}{*}{ FAILURE } & \multirow{2}{*}{$\begin{array}{l}\text { INFORMATION } \\
\text { REQUIRED }\end{array}$} & \multicolumn{2}{|c|}{ POSSIBLE FEEDBACK } & \multirow[t]{2}{*}{ ACTION REQUIRED } \\
\hline & & & & Type & Reliability & \\
\hline \multirow{11}{*}{ 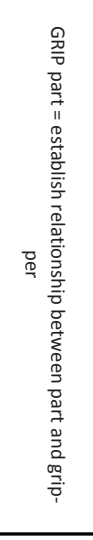 } & \multirow{2}{*}{$\begin{array}{l}\text { check if the part is } \\
\text { grasped }\end{array}$} & \multirow[t]{2}{*}{ part not grasped } & \multirow{2}{*}{$\begin{array}{l}\text { area of contact } \\
\text { part-gripper }\end{array}$} & visual & low & \multirow{2}{*}{$\begin{array}{l}\text { increase the closing } \\
\text { or the force }\end{array}$} \\
\hline & & & & grasping force & high & \\
\hline & \multirow[t]{2}{*}{$\begin{array}{l}\text { check if the part is } \\
\text { on the allowable } \\
\text { grasping surface }\end{array}$} & \multirow{2}{*}{$\begin{array}{l}\text { not be able to mount } \\
\text { the part because it is } \\
\text { grasped in the wrong } \\
\text { position }\end{array}$} & \multirow[t]{2}{*}{$\begin{array}{l}\text { range of area } \\
\text { where the part can } \\
\text { be grasped }\end{array}$} & $\begin{array}{l}\text { visual (sign on the parts; su- } \\
\text { perimpose on the part the } \\
\text { grasping area) }\end{array}$ & low & \multirow[t]{2}{*}{$\begin{array}{l}\text { move in the right } \\
\text { grasping place and } \\
\text { re-grasp it }\end{array}$} \\
\hline & & & & $\begin{array}{l}\text { grasping force (grasping po- } \\
\text { sition/force distribution) }\end{array}$ & high & \\
\hline & \multirow{2}{*}{$\begin{array}{l}\text { check if the part is } \\
\text { grasped with the } \\
\text { right orientation }\end{array}$} & \multirow{2}{*}{$\begin{array}{l}\text { not be able to mount } \\
\text { the part }\end{array}$} & \multirow{2}{*}{$\begin{array}{l}\text { position of part on } \\
\text { grasping surface }\end{array}$} & visual & low & \multirow{2}{*}{$\begin{array}{l}\text { re-grasp the part } \\
\text { with the right ori- } \\
\text { entation }\end{array}$} \\
\hline & & & & $\begin{array}{l}\text { grasping force (grasping po- } \\
\text { sition/force distribution) }\end{array}$ & high & \\
\hline & $\begin{array}{l}\text { check the gripping } \\
\text { force }\end{array}$ & $\begin{array}{l}\text { damage of the part } \\
\text { (deformation or } \\
\text { breaking) }\end{array}$ & force exerted & grasping force & high & substitute the part \\
\hline & \multirow{4}{*}{$\begin{array}{l}\text { check unwanted } \\
\text { movement of the } \\
\text { part (due to open- } \\
\text { ing of the gripper } \\
\text { or external force } \\
\text { on the part) }\end{array}$} & \multirow[t]{2}{*}{ 1.loosing of the part } & \multirow{2}{*}{$\begin{array}{l}\text { presence of the } \\
\text { part }\end{array}$} & visual & high & \multirow{4}{*}{$\begin{array}{l}\text { re-grasp of the } \\
\text { part/grasp another } \\
\text { part }\end{array}$} \\
\hline & & & & $\begin{array}{l}\text { grasping force (grasping po- } \\
\text { sition/force distribution) }\end{array}$ & low (high) & \\
\hline & & \multirow{2}{*}{$\begin{array}{l}\text { 2. sliding of the part } \\
\text { (can cause the im- } \\
\text { possibility to mount } \\
\text { the part) } \\
\end{array}$} & \multirow{2}{*}{$\begin{array}{l}\text { relative movement } \\
\text { between part and } \\
\text { gripper }\end{array}$} & visual & low & \\
\hline & & & & $\begin{array}{l}\text { grasping force (grasping po- } \\
\text { sition/force distribution) }\end{array}$ & low (high) & \\
\hline \multirow{4}{*}{ 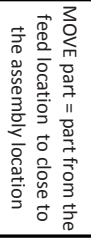 } & \multirow{4}{*}{$\begin{array}{l}\text { check if there is } \\
\text { contact of the } \\
\text { part/gripper with } \\
\text { other elements } \\
\text { present in the en- } \\
\text { vironment }\end{array}$} & 1.loosing of the part & \multirow[t]{4}{*}{$\begin{array}{l}\text { contact with other } \\
\text { element in the en- } \\
\text { vironment }\end{array}$} & visual & medium & \multirow[t]{4}{*}{$\begin{array}{l}\text { move far from the } \\
\text { other elements }\end{array}$} \\
\hline & & \multirow[t]{2}{*}{ 2.sliding of the part } & & & & \\
\hline & & & & interaction force & high & \\
\hline & & $\begin{array}{l}\text { 3.damage of the part } \\
\text { or the gripper }\end{array}$ & & & & \\
\hline \multirow{2}{*}{ 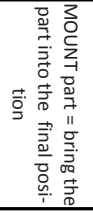 } & $\begin{array}{l}\text { check if the part is } \\
\text { approaching cor- } \\
\text { rectly to the as- } \\
\text { sembly position } \\
\end{array}$ & $\begin{array}{l}\text { damage of part (de- } \\
\text { formation or break- } \\
\text { ing) }\end{array}$ & $\begin{array}{l}\text { contact with other } \\
\text { element in the en- } \\
\text { vironment }\end{array}$ & interaction force & high & \multirow[t]{2}{*}{$\begin{array}{l}\text { move far from the } \\
\text { other elements }\end{array}$} \\
\hline & $\begin{array}{l}\text { check if the part is } \\
\text { correctly posi- } \\
\text { tioned in the as- } \\
\text { sembly position }\end{array}$ & $\begin{array}{l}\text { the part is positioned } \\
\text { in the wrong posi- } \\
\text { tion: wrong assembly }\end{array}$ & position of the part & visual & medium & \\
\hline \multirow{3}{*}{ 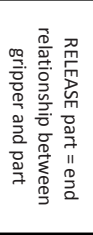 } & \multirow{2}{*}{$\begin{array}{l}\text { check if the gripper } \\
\text { is not in contact } \\
\text { with the object }\end{array}$} & \multirow{2}{*}{$\begin{array}{l}\text { the part is not re- } \\
\text { leased/it is released } \\
\text { in wrong position: } \\
\text { wrong assembly }\end{array}$} & $\begin{array}{l}\text { presence of the } \\
\text { part }\end{array}$ & visual & medium & $\begin{array}{l}\text { adopt some releas- } \\
\text { ing strategies [15] }\end{array}$ \\
\hline & & & & grasping force & medium & \\
\hline & $\begin{array}{l}\text { check if there are } \\
\text { unwanted dis- } \\
\text { placements or } \\
\text { forces on the ob- } \\
\text { ject }\end{array}$ & $\begin{array}{l}\text { the part is released in } \\
\text { the wrong position }\end{array}$ & position of the part & visual & medium & $\begin{array}{l}\text { adopt some releas- } \\
\text { ing strategies [15] }\end{array}$ \\
\hline
\end{tabular}

From Table 1 is evident how the complete presence of feedback (vision, grasping force and interaction force) can be useful or even necessary to successfully carry out the assembly tasks. 
Despite visual feedback is potentially able to detect most of the common failures, it does not always ensure a high reliability in terms of efficacy (e.g. to check little movement of the object on the grasping surface) or efficiency (e.g. giving an immediate feedback when the part is not grasped because the gripper has to move far from the grasping position before the part is recognized as not grasped). Furthermore, visual control may no longer be obtainable (e.g. when an obstacle blocks the view or because of the limitation related to the trade off between depth of focus and magnification). Often, the visual control is usually available during the first stages of an assembly operation (i.e. grasping of the parts and moving towards the final location) but not anymore in the final ones (i.e. the mounting and the releasing of the parts) for the narrow and inaccessible spaces in which some microassembly tasks take place.

On the other hand, Table 1 points out that the grasping and the interaction force feedback remain active during the entire assembly process in any assembly locations. Furthermore, these force feedbacks are usually more reliable than the visual feedback because these are more effective and efficient in detecting the failures.

\section{Grasping and Interaction Force Challenges}

Different challenges in the grasping and interaction force sensing need research efforts to assure the successful execution of many microassembly tasks.

A first requirement is the capability of the gripper to detect the position and the orientation of the object on the grasping surface. This information highlights if the object is grasped in the correct place for carrying out the assembly task and if it is safely grasped (Fig. 2). Such capabilities would give the possibility to detect unwanted movements of the object on the grasping surface due to external force.

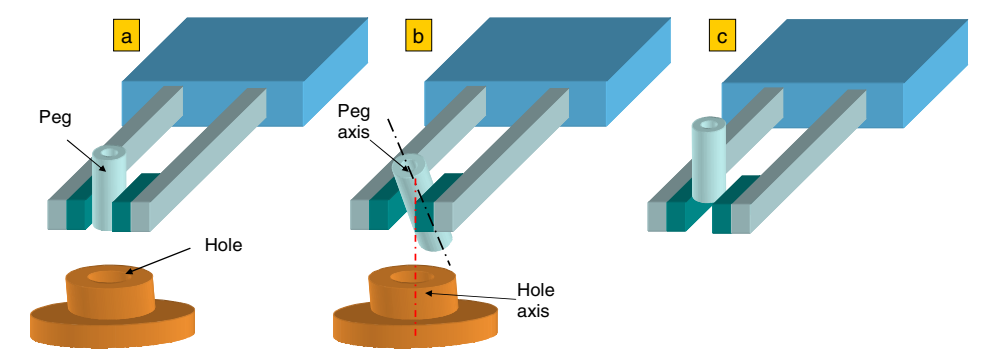

Fig. 2. Tasks in which the knowledge of the grasping position and orientation is important: a) the peg can not be inserted in the hole due its position on the grasping surface; b) the peg orientation does not allow the insertion in the hole because the axis of the peg is not coaxial with the axis of the hole (the gripper must orientate the peg); c) the object is close to the grasping surface edge and risk to be loosen.

A second requirement is the detection of the grasping force distribution on the object surface. If the object is not correctly grasped or it has different stiffness and fragility on different locations (Fig. 3), the simple control of the global grasping force can be not enough to avoid breaking or damaging the micro-parts. 

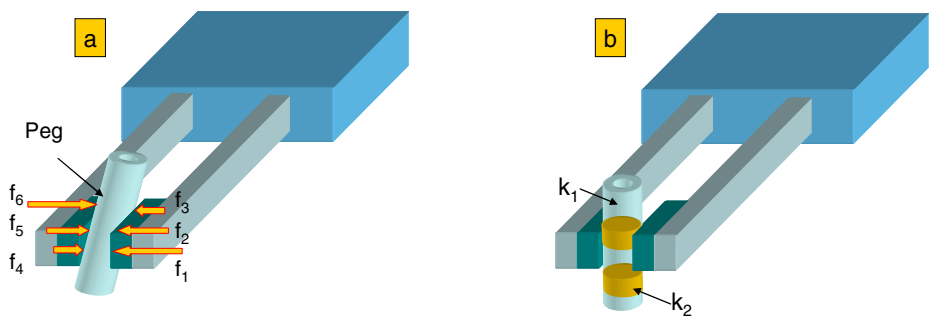

Fig. 3. Examples of situation in which the knowledge of the distribution of the grasping force is important to avoid damaging the micro-parts: a) the grasping force is not exerted uniformly on the micro-parts; b) the micro-parts have difference in stiffness in various location

A third requirement is to provide the same handling tool with the capability of monitoring both the grasping and interaction force. This capability would drastically improve tasks such as peg-in-hole insertion of fragile parts with low clearance and engagement of micro-gears. Actually, till now these two forces are usually detected by separate devices as pointed out in Section 2. This means that the gripper with grasping sensing and the device for the interaction force sensing are produced separately. Then the gripper has to be mounted (e.g. by mechanical connection or gluing) on the interaction force sensing device and the interaction sensing device fixed on the manipulator. Since these mounting operations are not simple due to the fragility and the (often) submillimeter dimension of the devices, inaccuracies and offsets affecting the grasping and interaction force sensing performance can arise.

\section{New Devices for Position Detection on the Grasping Surface}

In order to provide the gripper with the capability of detecting the object grasping position some new sensors have been developed by the authors [16], [17]. The sensors are fabricated with well known silicon based technologies and can be integrated in microgrippers with IC-compatible process without any post processing assembly tasks.

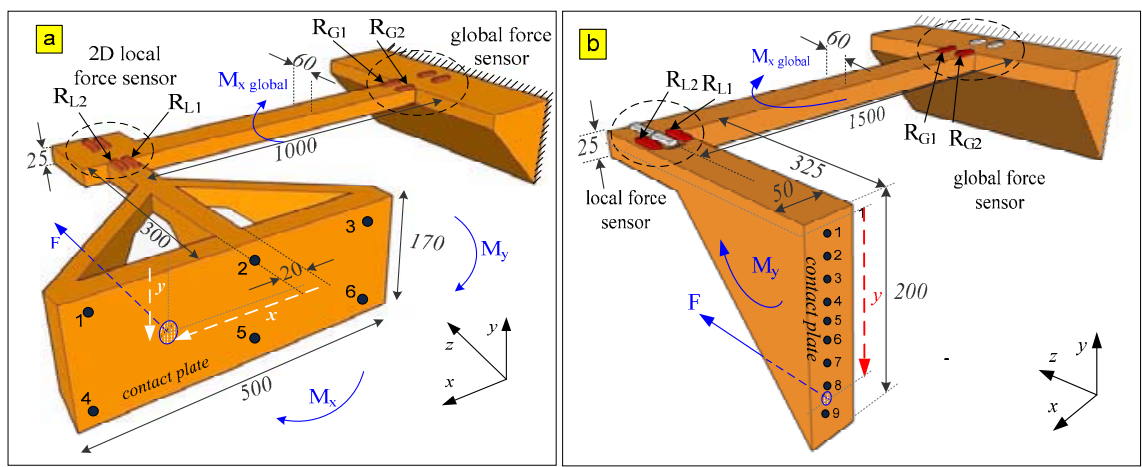

Fig. 4. Schematic drawing of the developed devices for detecting the contact position and the force acting on the contact plate 
The devices reported in [16], [17] and shown in Fig. 4 can give microgrippers the capability of detecting simultaneously the contact position and the perpendicular force acting on the contact plate by means of two piezoresistor sensors. The structure of the device is composed of an L-shape beam and a deep vertical contact plate (grasping surface). Piezoresistors pairs for local force sensor $\left(\mathrm{R}_{\mathrm{L} 1}, \mathrm{R}_{\mathrm{L} 2}\right)$ and global force sensor $\left(\mathrm{R}_{\mathrm{G} 1}, \mathrm{R}_{\mathrm{G} 2}\right)$, are positioned on the beam. The global force sensor detects the contact force $F$ in the $\mathrm{z}$ direction acting on the vertical contact plate while the local force sensor the contact position of the object on the contact plate. Both the two sensors consist of four piezoresistors in a Wheatstone bridge configuration. The position sensor of the device shown in Fig. 4a monitors the contact position along both $x$ and $y$ axis while the one of Fig. $4 \mathrm{~b}$ detects the position along the $y$ axis only.

Both devices were characterized with tests in which either a needle or a microsphere was used to exert a force perpendicular to the contact plate in the points shown in the drafts of Fig. 4 (1-6 in Fig. 4a and 1-9 in Fig. 4b). In the characterization tests the two sensors were supplied with an input voltage of $1 \mathrm{~V}$. The stress induced in the two sensors by the force was detected by monitoring the variation of resistance of the piezoresitors; then, the contact position and the global force can be computed.

The results about the relation between the real and the detected contact position are reported in Fig. 5. For the two devices different levels of force (corresponding to different levels of displacement) have been applied in each tested point. The maximum error between real and measured position is $20 \mu \mathrm{m}$ for the first device (Fig. 5a) and $10 \mu \mathrm{m}$ for the second one (Fig. 5b). These errors are supposed to be due to: i) the friction force between the object and the contact plate that induces extra stress on the sensor; ii) noise in the signal; iii) resolution of the lock-in amplifiers used to detect the signals.
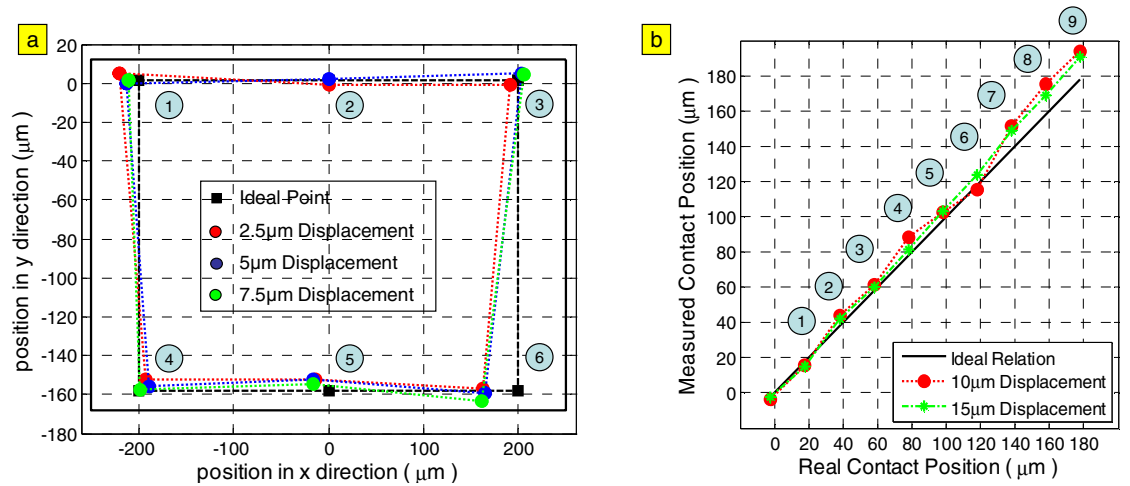

Fig. 5. Comparison between actual and measured contact positions on the contact plate of the devices shown in Fig.4a (a) and Fig.4b (b). Different forces corresponding to different displacements have been applied in each investigated point.

With regard to the force, the devices can detect a maximum force of $4 \mathrm{mN}$ (the first) and $3 \mathrm{mN}$ (the second). The maximum error for the force estimation is evaluated in $15 \%$ for the first one and in $10 \%$ for the second one. 


\section{Conclusions and Future Developments}

In this paper the advantages of a complete force feedback (grasping and interaction force) in microassembly tasks have been described and discussed. Some grasping and interaction force challenges have been highlighted and devices developed by the authors that tackle some of these challenges shown as well.

Future development aims at implementing the force feedback improvement described in the paper. The developed sensors for the detection of the position of the grasped micro-object will be integrated and tested in microgrippers. Gripper solutions with both grasping force sensing and interaction force detection along many DOF will be studied and developed as well.

\section{Acknowledgement}

The authors wish to thank the PME technical staff and the DIMES IC Process Group for their precious help in the fabrication and tests of the devices. Special thanks are due to Dr. Jia Wei and Prof. Lina Sarro for their support and the useful discussions in the research. Our gratitude to MicroNed program (www.microned.nl) for financing this research.

\section{References}

1. Rabenorosoa, K., Haddab, Y., Lutz, P.: A Low Cost Coarse/Fine Piezoelectrically Actuated Microgripper with Force Measurement Adapted to Eupass Control Structure. In: Proc. of IPAS 2008, Chamonix (France), February 10-13, pp. 235-242 (2008)

2. Probst, M., Hürzeler, C., Borer, R., Nelson, B.J.: A Microassembly System for the Flexible Assembly of Hybrid robotic Mems Devices. Int. Journal of Optomechatronics 3(2), 69-90 (2009)

3. Sieber, A., Valdastri, P., Houston, K., Eder, C., Tonet, O., Menciassi, A., Dario, P.: A novel haptic platform for real time bilateral biomanipulation with a MEMS sensor for triaxial force feedback. Sensors and Actuators A 142, 19-27 (2008)

4. Voyles, R.M., Hulst, S.: Micro/macro force-servoed gripper for precision photonics assembly and analysis. Robotica 23(4), 401-408 (2005)

5. Keller, C.G., Howe, R.T.: Hexsil Tweezers For Teleoperated Microassembly. In: Proc. of 10th IEEE Int. Workshop on Micro Electro Mechanical Systems (MEMS 1997), Nagoya (Japan), January 26-30, pp. 72-77 (1997)

6. Kim, K., Liu, X., Zhang, Y., Cheng, J., Yu Wu, X., Sun, Y.: Elastic and viscoelastic characterization of microcapsules for drug delivery using a force-feedback MEMS microgripper. Biomedical Microdevices 11(2), 421-427 (2009)

7. Kim, D.H., Lee, M.G., Kim, B., Sun, Y.: A superelastic alloy microgripper with embedded electromagnetic actuators and piezoelectric force sensors: a numerical and experimental study. Smart Material and Structures 14, 1265-1272 (2005)

8. Kyung, J.H., Ko, B.G., Ha, Y.H., Chung, G.J.: Design of a microgripper for micromanipulation of microcomponents using SMA wires and flexible hinges. Sensors and Actuators A $141,144-150(2008)$ 
9. Beyeler, F., Neild, A., Oberti, S., Bell, D.J., Sun, Y., Dual, J., Nelson, B.J.: Monolithically Fabricated Microgripper with Integrated Force Sensor for Manipulating Microobjects and Biological Cells Aligned in an Ultrasonic Field. Journal of MEMS 16(1), 7-15 (2007)

10. Chu Duc, T., Lau, G.K., Creemer, J.F., Sarro, P.M.: Electrothermal microgripper with large jaw displacement and integrated force sensors. Journal of MEMS 17, 1546-1555 (2008)

11. Beyeler, F., Muntwyler, S., Nelson, B.J.: Design and Calibration of a Microfabricated 6Axis Force-Torque Sensor for Microrobotic Applications. In: 2009 IEEE Int. Conf. on Robotics and Automation (ICRA 2009), Kobe (Japan), May 12-17 (2009)

12. Viet Dao, D., Toriyama, T., Wells, J., Sugiyama, S.: Silicon Piezoresistive Six-Degree of Freedom Micro Force-Moment Sensor. Sensors and Materials 15(3), 113-135 (2003)

13. Shen, Y., Xi, N., Lai, K.W.C., Li, W.J.: A novel PVDF microforce/force rate sensor for practical applications in micromanipulation. Sensor Review 24(3), 274-283 (2004)

14. http://www.ati-ia.com/products/ft/ft_models.aspx?id=Nano17 (last access 14 October 2009)

15. Fantoni, G., Porta, M.: A critical review of releasing strategies in microparts handling. In: Proc. of IPAS 2008, Chamonix (France), February 10-13, pp. 223-234 (2008)

16. Porta, M., Wei, J., Tichem, M., Sarro, P.M., Staufer, U.: Vertical Contact Position Detection and Grasping Force Monitoring for Microgripper Applications. In: Proc. of IEEE Sensors 2009, Christchurch (New Zeeland), October 25-29 (2009)

17. Wei, J., Porta, M., Tichem, M., Sarro, P.M.: A Contact Position Detection and Interaction Force Monitoring Sensor for Microassembly Applications. In: Proc. of Transducer 2009, Denver (CO, USA), June 21-25, pp. 2385-2388 (2009) 